\title{
Diabetes as a Risk Factor for Cardiovascular Events in Patients Receiving Permanent Pacemaker - A Propensity Score-Matched Cohort Study
}

\section{Huang-Chung Chen ( $\nabla$ chc3@cgmh.org.tw )}

Chang Gung Memorial Hospital Kaohsiung Branch https://orcid.org/0000-0002-4423-9246

\section{Wen-Hao Liu}

Chang Gung Memorial Hospital Kaohsiung Branch

\section{Chien-Hao Tseng}

Chang Gung Memorial Hospital Kaohsiung Branch

\section{Yung-Lung Chen}

Chang Gung Memorial Hospital Kaohsiung Branch

\section{Wei-Chieh Lee}

Chang Gung Memorial Hospital Kaohsiung Branch

\section{Yen-Nan Fang}

Chang Gung Memorial Hospital Kaohsiung Branch

\section{Shaur-Zheng Chong}

Chang Gung Memorial Hospital Kaohsiung Branch

\section{Mien-Cheng Chen}

Chang Gung Memorial Hospital Kaohsiung Branch

\section{Original investigation}

Keywords: pacemaker, type 2 diabetes, cardiovascular events, heart failure hospitalization, acute myocardial infarction

Posted Date: August 25th, 2021

DOl: https://doi.org/10.21203/rs.3.rs-815490/v1

License: (우 This work is licensed under a Creative Commons Attribution 4.0 International License. Read Full License 


\section{Abstract}

\section{Background:}

Type 2 diabetes was associated with higher risk for permanent pacemaker (PPM) implantation. We aimed to compare the clinical outcomes between diabetic and non-diabetic patients receiving PPM treatment.

\section{Methods:}

Between January 2003 and December 2017, 1742 patients receiving naïve PPM treatment comprised this retrospective cohort study and were categorized into two groups by the presence or absence of diagnosis of diabetes: diabetic group $(n=632,36.3 \%)$ and non-diabetic group $(n=1110,63.7 \%)$. The primary outcome was cardiovascular events including heart failure (HF) hospitalization and acute myocardial infarction (AMI). Propensity score matching (PSM) was applied to reduce selection bias between the study groups.

\section{Results:}

During a mean follow-up of $7.8 \pm 4.8$ years, there were 264 cardiovascular events. A total of 746 patients with a 1:1 paired ratio between diabetic and non-diabetic groups were analyzed in the propensity score-matched series. After PSM, the incidence of cardiovascular events was higher in the diabetic group compared to the non-diabetic group $(18.8 \%$ vs. $12.3 \%, \mathrm{P}=0.015)$. Moreover, the incidence of $\mathrm{HF}$ hospitalization was higher in the diabetic patients compared to the non-diabetic patients ( $15.3 \%$ vs. $10.2 \%, P=0.037)$, whereas the incidence of AMI did not differ between the diabetic and non-diabetic groups ( $3.5 \%$ vs. $2.1 \%, P=0.268$ ). After adjustments for covariates in multiple Cox regression analysis, diabetes remained as an independent predictor for cardiovascular events [hazard ratio, 1.54; 95\% confidence interval, 1.04-2.29; $\mathrm{P}=0.031$ ].

\section{Conclusions:}

In this cohort study of patients with naïve PPMs implantation, diabetes increased 1.54-fold risk of cardiovascular events in PPM recipients, especially for HF hospitalization.

\section{Introduction}

Diabetes mellitus is a serious chronic disease with an imperative influence on health of human being in the worldwide. Owing to ageing population, economic development and change of lifestyle, the growth in global and regional prevalence of type 2 diabetes markedly increased [1-4]. The number of patients with type 2 diabetes had doubled during the past two decades, and half of people with diabetes are not even aware that they have diabetes [1, 4]. Diabetes is a well-known risk factor for cardiovascular events, such as acute myocardial infarction (AMI) and heart failure (HF) $[5,6]$. Previous studies demonstrated that lethal tachyarrhythmia occurs commonly in diabetic patients, possibly related to myocardial ischemia and sympathoadrenal activation in response to hypoglycemia [7-8]. On the other hand, an association between bradyarrhythmia and diabetes has also been reported, which is possibly caused by microangiopathy and increased cholinergic sensitivity [9-11]. From a national diabetes registry study, Rautio et al. reported that type 2 diabetes was associated with 1.6-fold higher risk for permanent pacemaker (PPM) treatment after adjustments for age, sex, and other factors [12]. However, the difference in cardiovascular outcomes between 
type 2 diabetic patients and non-diabetic patients receiving PPM treatment remains unexplored. Moreover, type 2 diabetes as an independent risk factor for cardiovascular events in pacemaker recipients remains unexplored. Accordingly, we conducted this retrospective cohort study to investigate and compare the clinical outcomes between diabetic and non-diabetic patients receiving PPM treatment after propensity score matching (PSM). Moreover, this study also aimed to identify whether type 2 diabetes was a risk factor for cardiovascular events in PPM recipients.

\section{Methods}

\section{Study population}

This retrospective cohort study enrolled 2706 consecutive patients receiving cardiac implantable electronic devices implantation in our hospital between January, 2003 and December, 2017. A total of 964 patients, including 191 patients with implantable intracardiac defibrillators, 78 patients with cardiac resynchronization therapy and 695 patients with replacement of generator, were excluded (Figure 1). Finally, 1742 patients receiving single ventricular or dual chamber PPMs comprised this retrospective cohort study population and were categorized into two groups by the presence or absence of diagnosis of type 2 diabetes at the time of PPM implantation: diabetic group $(n=632,36.3 \%)$, and non-diabetic group $(n=1110,63.7 \%)$ (Figure 1). The standard protocol for PPM implantation in our center had been described in our previous study [15], mainly right ventricular lead placed at right ventricular outflow tract or high septum.

\section{Definitions}

Based on recommendations from the American Diabetes Association [16], diabetes was defined as prescription for oral antidiabetic drugs or insulin, or $\mathrm{HbA} 1 \mathrm{c} \geq 6.5 \%(48 \mathrm{mmol} / \mathrm{mol})$, or fasting plasma glucose level $\geq 126 \mathrm{mg} / \mathrm{dl}(7.0 \mathrm{mmol} / \mathrm{L})$, or a random plasma glucose $\geq 200 \mathrm{mg} / \mathrm{dL}(11.1 \mathrm{mmol} / \mathrm{L})$ with classic symptoms of hyperglycemia or hyperglycemic crisis during hospitalization for PPM implantation. According to the guidelines of Kidney Disease: Improving Global Outcomes [17], microalbuminuria was defined as at least two positive results obtained within 1 year and was defined as an albumin-to-creatinine ratio of $30-300 \mathrm{mg} / \mathrm{g}$ (3-30 mg/mmol); macroalbuminuria was defined as an albumin-to-creatinine ratio $\geq 300 \mathrm{mg} / \mathrm{g}(>30 \mathrm{mg} / \mathrm{mmol})$. Estimated glomerular filtration rate (eGFR) was estimated from the creatinine value and calculated using the Chronic Kidney Disease Epidemiology Collaboration equation [18]. Chronic kidney disease (CKD) was defined as eGFR lower than $60 \mathrm{~mL} / \mathrm{min} / 1.73 \mathrm{~m} 2$ without renal replacement therapy, and end-stage renal disease as the need for peritoneal dialysis, hemodialysis, or renal transplantation. Hyperlipidemia was defined as total cholesterol $\geq 240 \mathrm{mg} / \mathrm{dL}$, low density lipoprotein $\geq 150 \mathrm{mg} / \mathrm{dL}$, or triglyceride $\geq 200 \mathrm{mg} / \mathrm{dL}$, or on lipid lowering medications [19]. Valvular heart disease was defined as moderate to severe regurgitation or stenosis of aortic, mitral or tricuspid valves. Cardiovascular surgery included coronary artery bypass graft and valvular surgery. Chronic lung disease was defined as a history of asthma, chronic obstructive pulmonary disease, or pulmonary fibrosis.

\section{Clinical outcomes}

The primary outcome of this study was cardiovascular events of patients after PPM implantation. Cardiovascular events included hospitalization related to HF event of New York Heart Association functional 
class of III-IV, or AMI. The secondary outcomes of this study included pacing-induced cardiomyopathy, cerebrovascular accident, cardiovascular mortality and all-cause mortality. Pacing-induced cardiomyopathy was defined as a $\geq 10 \%$ decrease of the baseline left ventricular ejection fraction (LVEF) with a resultant LVEF $<50 \%$. Cerebrovascular accident was defined as an episode of transient ischemic attack, ischemic stroke, intracranial hemorrhage, or any incident finding by images, including brain computed tomography or magnetic resonance imaging after PPM implantation. Cardiovascular mortality was defined as death from AMI, HF, refractory ventricular arrhythmias, or cardiac arrest. After PPM implantation, patients were followed up monthly for the first three months and then every three to six months until clinical outcomes of interest, death, loss to follow up, or the latest date in the dataset (31 December, 2020), whichever came first.

\section{Study covariates}

Baseline variables considered in the analyses included patient's age, sex, body mass index and comorbidities associated with clinical outcomes including hypertension, hyperlipidemia, coronary artery disease, HF, atrial fibrillation, valvular heart disease, chronic kidney disease, history of cardiovascular surgery, cancer, and chronic lung disease. The prescription for medication, such as beta-blocker, anti-hypertensive drugs, diuretic agents and lipid-lowering agents, laboratory data including hemoglobin and serum creatinine, the indication and lead number of PPM, baseline and pacing QRS duration were also obtained.

\section{Statistical analysis}

Continuous variables are expressed as a mean \pm standard deviation or percentages. The clinical characteristics of the study groups were compared using the independent t-test for continuous variables and Chi-square test or Fisher's exact test for categorical variables. PSM was applied to reduce selection bias between the study groups. Using NCSS 10 Statistical Software (LLC, Kaysville, Utah, USA), the greedy method was used for matching at a 1:1 ratio between the study groups with a caliper width 0.2-fold the standard deviation of the propensity score between the study groups. The standardized mean difference was used to evaluate covariate balance after PSM, and a value of $>0.1$ indicated meaningful imbalance after PSM [20]. The incidences of cardiovascular events during long-term follow-up were expressed with Kaplan-Meier survival curves and compared by log-rank test. The significance of each variable in predicting cardiovascular events was tested using the Cox proportional hazards model, analyzed with forward option. The multiple Cox regression analysis included parameters that had $P$ values $<0.1$ in univariate analysis. A two-sided $P$ value $<0.05$ was considered statistically significant. SPSS for Windows (version 22.0; SPSS Inc., Chicago, IL, USA) was used to perform the statistical analysis.

\section{Results}

\section{Baseline characteristics of the study patients with and without type 2 diabetes}

Table 1 lists the clinical characteristics of the study patients before and after PSM. Before PSM, the mean age of the patient population was $73 \pm 11$ years and $48.6 \%$ of the study patients were male. There were 632 (36.3\%) diabetic patients, which were under diet control alone $(12.8 \%)$, oral antidiabetic drugs $(74.7 \%)$ or insulin-based therapy (12.5\%), and 1110 (63.7\%) non-diabetic patients (Figure 1). The diabetic group had more patients with overweight and higher prevalence of hypertension, hyperlipidemia, coronary artery disease, CKD 
and end-stage renal disease (all $\mathrm{P}<0.001)$ compared to the non-diabetic group. The diabetic group also had a higher prevalence of history of HF ( $P=0.033)$, atrial fibrillation ( $P=0.007)$, and cerebrovascular accident $(P=0.028)$ compared to the non-diabetic group. The diabetic group had more prescription for beta-blocker $(P=0.001)$, angiotensin converting enzyme inhibitors/angiotensin receptor blocker (ACEi/ARB), diuretic agents, and statin (all $\mathrm{P}<0.001$ ). The diabetic group had higher serum creatinine, hemoglobin $\mathrm{A} 1 \mathrm{C}$ and triglyceride, and higher prevalence of albuminuria including microalbuminuria and macroalbuminuria (all $\mathrm{P}<0.001$ ) compared to the non-diabetic group. The diabetic group had lower levels of hemoglobin, eGFR, low-density lipoprotein and high-density lipoprotein (all $\mathrm{P}<0.001$ ) compared to the non-diabetic group. The diabetic group had higher prevalence of atrioventricular block $(P=0.001)$, larger number of PPM leads $(P=0.025)$ and wider baseline and pacing $Q R S$ durations $(P=0.037$ and $P=0.019$, respectively) compared to the non-diabetic group. The diabetic group had larger pre-procedural left atrial size $(P=0.010)$ and LV end-diastolic volume $(P=0.049)$, and lower preprocedural LVEF $(P=0.042)$ compared to the non-diabetic group (Table 1).

In the cohort after 1:1 PSM, 373 diabetic and non-diabetic pairs were analyzed. The baseline characteristics were balanced in the matched groups (Table 1). After PSM, the matched diabetic group still had lower lowdensity lipoprotein $(P=0.001)$ and high-density lipoprotein $(P=0.005)$ and higher triglyceride $(P=0.049)$ levels as well as higher prevalence of albuminuria $(P<0.001)$ compared to the matched non-diabetic group $($ Table 1$)$.

\section{Clinical outcomes of the study patients before and after PSM}

During a mean follow-up period of $7.8 \pm 4.8$ years, before PSM, the incidence of cardiovascular events was higher in the diabetic group compared to the non-diabetic group (19.8\% vs. $12.5 \%, \mathrm{P}<0.001)$ (Table 2$)$, and the incidences of pacing-induced cardiomyopathy, cardiovascular mortality, and all-cause mortality were all higher in the diabetic group compared to the non-diabetic group (Table 2). After PSM, the incidence of cardiovascular events was still higher in the diabetic group compared to the non-diabetic group ( $18.8 \%$ vs. $12.3 \%, P=0.015)$ (Table 2). The diabetic patients had a higher incidence of HF hospitalization compared to the non-diabetic patients (15.3\% vs. $10.2 \%, P=0.037)$, whereas the incidence of AMI did not differ between the two groups (Table 2). After PSM, the incidences of secondary outcomes, including pacing-induced cardiomyopathy, cerebrovascular accident, cardiovascular mortality and all-cause mortality, did not differ between the two groups (Table 2). The Kaplan-Meier curve analysis for cardiovascular events showed that diabetic patients had a higher cumulative incidence of cardiovascular events compared to non-diabetic patients before and after PSM (log-rank test, $\mathrm{P}<0.001$ and $\mathrm{P}=0.001$, respectively) (Figure 2a and Figure 2d). Moreover, the diabetic group had a higher cumulative incidence of HF hospitalization compared to the non-diabetic group before and after PSM (log-rank test, $P<0.001$ and $P=0.005$, respectively) (Figure $2 b$ and Figure $2 e$ ). However, the cumulative incidence of AMI did not differ between the two groups before and after PSM (Figure 2c and 2f).

\section{Clinical predictors of cardiovascular events in the propensity score-matched patients receiving pacemakers}

In this study, there were 264 cardiovascular events during follow-up (Table 2). Patients with cardiovascular events were older $(P=0.004)$ and had higher prevalence of diabetes $(P=0.008)$, coronary artery disease $(P<0.001)$, history of HF ( $P<0.001)$, atrial fibrillation $(P=0.005)$, CKD $(P<0.001)$ and albuminuria $(P<0.001)$, wider pacing $Q R S$ duration $(P=0.007)$, larger pre-procedural left atrium $(P=0.035)$ and $L V$ end-diastolic volume $(P=0.037)$, lower LVEF $(P=0.005)$ and more prescription for ACEi/ARB $(P<0.001)$ and diuretic agents $(P<0.001)$ than patients without cardiovascular events (Table 3). After adjustments for age, sex, diabetes, coronary artery 
disease, $\mathrm{HF}$, atrial fibrillation, valvular heart disease, CKD, albuminuria, pacing QRS duration, pre-procedural left atrium and LV end-diastolic volume, LVEF, administration of ACEi/ARB and diuretic agents (all $P<0.1)$ in multiple Cox regression analysis, independent predictors of cardiovascular events were female [hazard ratio (HR), 1.72; 95\% confidence interval $(95 \% \mathrm{Cl}), 1.14-2.61 ; \mathrm{P}=0.010]$, diabetes [HR, 1.54; $95 \% \mathrm{Cl}, 1.04-2.29$; $\mathrm{P}=0.031]$, coronary artery disease [HR, 1.66; $95 \% \mathrm{Cl}, 1.09-2.52$; $\mathrm{P}=0.017]$, $\mathrm{HF}$ history [HR, 2.12; 95\% Cl, 1.38-3.53; $P=0.004], C K D$ [HR, 2.01; 95\% Cl, 1.32-3.07; $P=0.001]$, albuminuria [HR, 1.56; 95\% $\mathrm{Cl}, 1.00-2.43 ; \mathrm{P}=0.049]$, and prescription for ACEi/ARB [HR, 1.82; 95\% Cl, 1.19-2.78; $\mathrm{P}=0.006]$ (Table 3).

\section{Discussion}

In this cohort study, the prevalence of diabetes was $36.3 \%$, over one-third of naïve PPM recipients. During a mean follow-up of $7.8 \pm 4.8$ years, after PSM, the incidences of cardiovascular events and HF hospitalization were significantly higher in the diabetic group compared to the non-diabetic group. Moreover, the cumulative incidences of cardiovascular events and HF hospitalization were significantly higher in the diabetic matched group compared to the non-diabetic matched group. Furthermore, by multiple Cox regression analysis, diabetes remained as an independent predictor for cardiovascular events in patients after naïve PPM implantation.

\section{The prevalence of diabetes in patients receiving pacemakers}

The global prevalence of diabetes is rising from $8 \%$ in 1980 to $9.3 \%$ in 2019 , and is estimated to be $10.9 \%$ by 2045 , which may be attributable to population growth and ageing $[1,2]$. In the Taiwanese population, the annual prevalence of diabetes increased significantly from $5.8 \%$ in 2000 to $8.3 \%$ in 2007, especially in the subgroup of men, age $\geq 80$ years, and individuals residing in aging society areas [3]. In the elderly $\geq 65$ years, around $15 \%-20 \%$ of people live with diabetes $[1,21]$. In this study, PPM recipients were aged and the prevalence of diabetes was $36.3 \%$, which was higher than general population [1-3,21] and was compatible with previous data of PPM recipients $[13,14]$. Moreover, similar to other reports [1-3,21], the trend in the prevalence of diabetes in this study, also increased from 28.8\% (between 2003 and 2007) and 36.0\% (between 2008 and 2012) to $41.4 \%$ (between 2013 and 2017).

Prior study reported that diabetes was possibly associated with sinus nodal dysfunction and cardiac conduction abnormalities [9-11,22]. Movahed et al. reported that the incidence of complete atrioventricular block in the diabetic patients was $1.1 \%$, which was 3 -fold increased risk compared to the non-diabetic patients [11]. Diabetic patients of this study had a higher prevalence of atrioventricular block compared to non-diabetic patients ( $44.0 \%$ vs. $35.8 \%, P=0.001$ ) (Table 1 ), similar to other reports [10-12]. From a national diabetes registry study, Rautio et al. reported that diabetes increased 1.6-fold risk for implantation of PPM after adjustments for age, sex, and other factors [12]. Therefore, type 2 diabetes is a risk factor for PPM implantation and vigilant follow-up for bradyarrhythmia in diabetic patients is necessary.

\section{Heart failure hospitalization in diabetic patients after pacemaker implantation}

The prevalence of diabetes in HF patients is around $20 \%$, and diabetes increased 1.74 -fold risk and 1.95 -fold risk of HF in men and women, respectively $[6,23]$. The reasons for increasing risk of HF in diabetic patients included combined comorbidities such as hypertension, acceleration of the development of coronary 
atherosclerosis, and diabetic cardiomyopathy, which was related to microangiopathy, metabolic factors or myocardial fibrosis [23]. Moreover, a study using the National Readmission Database showed that the most common cause for readmission in PPM recipients was HF hospitalization [24]. In this study, we showed that the incidence of $\mathrm{HF}$ hospitalization was significantly higher in the diabetic group compared to the non-diabetic group before and after PSM. Diabetic cardiomyopathy is characterized by diastolic relaxation abnormalities in its early stage and later systolic dysfunction [25]. The pathophysiological mechanisms of diabetic cardiomyopathy include systemic metabolic disorders, inappropriate activation of the renin-angiotensinaldosterone system, subcellular component abnormalities, oxidative stress, inflammation and dysfunctional immune modulation and finally, interstitial fibrosis of cardiac tissue, which contributed to substantial cardiac stiffness with diastolic dysfunction and later, systolic dysfunction [25]. Furthermore, diabetes is an important phenotype for HF with preserved LVEF, and is also an independent predictor for HF hospitalization, despite under treatments of ACEi/ARB [26]. Interestingly, the study population in this study had preserved LVEF and the administration of ACEi/ARB was higher in the diabetic group compared to the non-diabetic group before PSM (Table 1). In this study, prescription for ACEi/ARB was an independent risk for cardiovascular events (Table 3). Of note, patients prescribed with ACEi/ARB were older and had higher prevalence of hypertension, hyperlipidemia and CKD, and had larger LV end-systolic volume and lower LVEF (even within the normal range) compared to those without prescribed with ACEi/ARB (supplementary Table 1), consequently worse clinical outcome. These findings deserve further investigations regarding angiotensin receptor-neprilysin inhibitor or sodium-glucose cotransporter 2 inhibitor in diabetic patients with preserved LVEF for PPM implantation $[27,28]$.

Right ventricular pacing is associated with HF hospitalization [29]. Recently, physiological pacing, such as His bundle pacing, has been reported to reduce HF hospitalization compared to right ventricular pacing [30]. Our study was the first to show that diabetes was an independent predictor for cardiovascular events, including HF hospitalization, in patients after right ventricular PPM implantation. Our findings provided the hypothesis for future studies of physiological pacing in diabetic patients who required PPM implantation.

\section{Other predictors for cardiovascular events in patients after pacemaker implantation}

Previous studies reported that type 2 diabetes was associated with higher risk of $\mathrm{HF}$ in women than men $[6,23]$. There are several potential explanations including poorer glycemic control in women, under-treatment for diabetic women contributing to the development of diabetic cardiomyopathy, prolonged exposure to hyperglycemia during the prediabetic state in women, diastolic dysfunction of LV more common in women and deteriorations in major cardiovascular risk factors in women than in men [6]. In this study, women, compared with men, had a 1.72-fold increased risk for cardiovascular events (Table 3), which was compatible with other studies $[6,23]$. In diabetic patients with diabetic nephropathy, the risk of cardiovascular events increased by the decline of eGFR and the presentation of macroalbuminuria [31]. This study showed that CKD and presentation of albuminuria were independent risk factors for cardiovascular events (Table 3 ). Therefore, regular follow-up of renal function and serial measurement for albuminuria for PPM recipients, especially in women, is necessary.

\section{Limitation}


In this study, some potential limitations existed. First, although this was a retrospective single-center study, the sample size was large. Still, the potential bias inherent to nonrandomized investigations cannot be excluded. However, we performed PSM to minimize the bias between diabetic and non-diabetic groups. Second, the compliance period and dosage of prescription for beta-blocker, ACEi/ARB, diuretic agents, and statin during follow-up period were not available in this study. Third, the duration of diagnosed diabetes before PPM implant was unknown. Finally, the pre-procedural echocardiographic parameters of diastolic function by tissue Doppler or speckle-tracking imaging were not performed.

\section{Conclusions}

In this cohort study of patients with naïve PPMs implantation, the incidences of cardiovascular events and HF hospitalization were significantly higher in the diabetic group compared to the non-diabetic group. Moreover, diabetes increased 1.54-fold risk of cardiovascular events in PPM recipients, especially for HF hospitalization.

\section{Abbreviations}

ACEi/ARB: Angiotensin converting enzyme inhibitors/angiotensin receptor blocker; AMI: Acute myocardial infarction; CKD: Chronic kidney disease; eGFR: Estimated glomerular filtration rate; HF: Heart failure; LVEF: Left ventricular ejection fraction; PPM: Permanent pacemaker; PSM : Propensity score matching

\section{Declarations}

\section{Acknowledgements}

We appreciate the Biostatistics Center, Kaohsiung Chang Gung Memorial Hospital, for assistance with the statistical analysis.

\section{Authors' contributions}

HCC contributed to analysis and interpretation of data., and wrote the manuscript. WHL and CHT contributed to discussion, reviewed and edited the manuscript. YLC, WCL, YNF, and SZC contributed to collection of data. MCC contributed to study design, and revised the manuscript critically for important intellectual content. All authors read and approved the final manuscript.

\section{Funding}

This research received no grant from any funding agency in the public, commercial or not-for-profit sectors.

\section{Availability of data and materials}

The datasets used and/or analyzed during the current study are available from the corresponding author on reasonable request.

Ethics approval and consent to participate 
The study protocol was approved by the Institutional Review Board of Chang Gung Medical Foundation (permit number: 202100907B0).

\section{Consent for publication}

Not applicable.

\section{Competing interests}

The authors declare that they have no competing interests.

\section{References}

1. Saeedi P, Petersohn I, Salpea P, Malanda B, Karuranga S, Unwin N, et al. Global and regional diabetes prevalence estimates for 2019 and projections for 2030 and 2045: Results from the International Diabetes Federation Diabetes Atlas, 9th edition. Diabetes Res Clin Pract. 2019;157:107843.

2. Danaei G, Finucane MM, Lu Y, Singh GM, Cowan MJ, Paciorek CJ, et al. National, regional, and global trends in fasting plasma glucose and diabetes prevalence since 1980: systematic analysis of health examination surveys and epidemiological studies with 370 country-years and $2 \cdot 7$ million participants. Lancet. 2011;378:31-40.

3. Lin CC, Li Cl, Hsiao CY, Liu CS, Yang SY, Lee CC, et al. Time trend analysis of the prevalence and incidence of diagnosed type 2 diabetes among adults in Taiwan from 2000 to 2007: a population-based study. BMC Public Health. 2013;13:318.

4. Zimmet PZ, Magliano DJ, Herman WH, Shaw JE. Diabetes: a 21st century challenge. Lancet Diabetes Endocrinol. 2014;2:56-64.

5. Haffner SM, Lehto S, Rönnemaa T, Pyörälä K, Laakso M. Mortality from coronary heart disease in subjects with type 2 diabetes and in nondiabetic subjects with and without prior myocardial infarction. $N$ Engl $J$ Med. 1998;339:229-34.

6. Ohkuma T, Komorita Y, Peters SAE, Woodward M. Diabetes as a risk factor for heart failure in women and men: a systematic review and meta-analysis of 47 cohorts including 12 million individuals. Diabetologia. 2019;62:1550-60.

7. Weidner K, Behnes M, Schupp T, Rusnak J, Reiser L, Bollow A, et al. Type 2 diabetes is independently associated with all-cause mortality secondary to ventricular tachyarrhythmias. Cardiovasc Diabetol. 2018;17:125.

8. Frier BM. Hypoglycaemia in diabetes mellitus: epidemiology and clinical implications. Nat Rev Endocrinol. 2014;10:711-22.

9. Wasada T, Katsumori K, Hasumi S, Kasanuki H, Arii H, Saeki A, et al. Association of sick sinus syndrome with hyperinsulinemia and insulin resistance in patients with non-insulin-dependent diabetes mellitus: report of four cases. Intern Med. 1995;34:1174-7.

10. Blandford RL, Burden AC. Abnormalities of cardiac conduction in diabetics. Br Med J (Clin Res Ed). 1984;289:1659. 
11. Movahed MR, Hashemzadeh M, Jamal MM. Increased prevalence of third-degree atrioventricular block in patients with type II diabetes mellitus. Chest. 2005;128:2611-4.

12. Rautio E, Gadler F, Gudbjörnsdottir S, Franzén S, Rydén L, Svensson AM, et al. Patients With Type 2 Diabetes Have an Increased Demand for Pacemaker Treatment: A Comparison With Age- and SexMatched Control Subjects From the General Population. Diabetes Care. 2020;43:2853-8.

13. Podlaha R, Falk A. The prevalence of diabetes mellitus and other risk factors of atherosclerosis in bradycardia requiring pacemaker treatment. Horm Metab Res Suppl. 1992;26:84-7.

14. Lear JT, Lawrence IG, Burden AC. Prevalence of diabetes in elderly patients requiring permanent cardiac pacemaker insertion. Acta Diabetol. 1996;33:169-70.

15. Chen HC, Chen YL, Guo BF, Tsai TH, Chang JP, Pan KL, et al. Thrombocytopenia, dual antiplatelet therapy, and heparin bridging strategy increase pocket hematoma complications in patients undergoing cardiac rhythm device implantation. Can J Cardiol. 2013;29:1110-7.

16. American Diabetes Association. 2. Classification and Diagnosis of Diabetes: Standards of Medical Care in Diabetes-2019. Diabetes Care. 2019;42:S13-S28.

17. Kidney Disease: Improving Global Outcomes (KDIGO) Diabetes Work Group. KDIGO 2020 Clinical Practice Guideline for Diabetes Management in Chronic Kidney Disease. Kidney Int. 2020;98:S1-S115.

18. Levey AS, Stevens LA, Schmid CH, Zhang YL, Castro AF 3rd, Feldman HI, et al. A new equation to estimate glomerular filtration rate. Ann Intern Med. 2009;150:604-12.

19. Li YH, Ueng KC, Jeng JS, Charng MJ, Lin TH, Chien KL, et al. 2017 Taiwan lipid guidelines for high risk patients. J Formos Med Assoc. 2017;116:217-48.

20. Austin PC. Balance diagnostics for comparing the distribution of baseline covariates between treatment groups in propensity-score matched samples. Stat Med. 2009;28:3083-107.

21. Sinclair A, Saeedi P, Kaundal A, Karuranga S, Malanda B, Williams R. Diabetes and global ageing among 65-99-year-old adults: Findings from the International Diabetes Federation Diabetes Atlas, 9th edition. Diabetes Res Clin Pract. 2020;162:108078.

22. Movahed MR. Diabetes as a risk factor for cardiac conduction defects: a review. Diabetes Obes Metab. 2007;9:276-81.

23. Bauters C, Lamblin N, Mc Fadden EP, Van Belle E, Millaire A, de Groote P. Influence of diabetes mellitus on heart failure risk and outcome. Cardiovasc Diabetol. 2003;2:1.

24. Pasupula DK, Rajaratnam A, Rattan R, Munir MB, Ahmad S, Adelstein E, et al. Trends in Hospital Admissions for and Readmissions After Cardiac Implantable Electronic Device Procedures in the United States: An Analysis From 2010 to 2014 Using the National Readmission Database. Mayo Clin Proc. 2019;94:588-98.

25. Jia G, Whaley-Connell A, Sowers JR. Diabetic cardiomyopathy: a hyperglycaemia- and insulin-resistanceinduced heart disease. Diabetologia. 2018;61:21-8.

26. Lejeune S, Roy C, Slimani A, Pasquet A, Vancraeynest D, Vanoverschelde JL, et al. Diabetic phenotype and prognosis of patients with heart failure and preserved ejection fraction in a real life cohort. Cardiovasc Diabetol. 2021;20:48. 
27. Solomon SD, McMurray JJV, Anand IS, Ge J, Lam CSP, Maggioni AP, et al. Angiotensin-Neprilysin Inhibition in Heart Failure with Preserved Ejection Fraction. N Engl J Med. 2019;381:1609-20.

28. Breakthrough results for empagliflozin confirm EMPEROR-Preserved as first and only successful trial for heart failure with preserved ejection fraction. 2021. https://www.boehringer-ingelheim.com/pressrelease/emperor-preserved-heart-failure-toplineresults. Accessed 6 July 2021.

29. Smit MD, Van Dessel PF, Nieuwland W, Wiesfeld AC, Tan ES, Anthonio RL, et al. Right ventricular pacing and the risk of heart failure in implantable cardioverter-defibrillator patients. Heart Rhythm. 2006;3:1397403.

30. Vijayaraman P, Naperkowski A, Subzposh FA, Abdelrahman M, Sharma PS, Oren JW, et al. Permanent Hisbundle pacing: Long-term lead performance and clinical outcomes. Heart Rhythm. 2018;15:696-702.

31. Sasso FC, Chiodini P, Carbonara O, De Nicola L, Conte G, Salvatore T, et al. High cardiovascular risk in patients with Type 2 diabetic nephropathy: the predictive role of albuminuria and glomerular filtration rate. Nephrol Dial Transplant. 2012;27:2269-74.

\section{Tables}

Table 1. Baseline characteristics of the study patients before and after propensity score matching 
Before matching

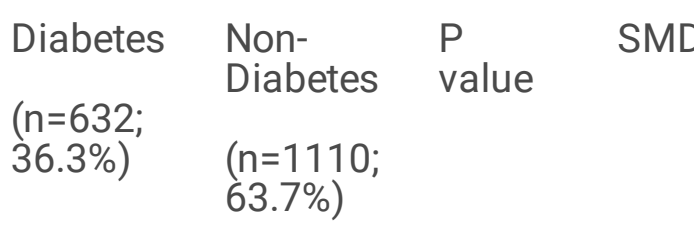

After matching

$\begin{array}{llll}\text { Diabetes } & \text { Non- } & P & \text { SMD } \\ (n=373) & \text { Diabetes } & \text { value } & \\ & (n=373) & & \end{array}$

\section{Baseline characteristics}

\begin{tabular}{|c|c|c|c|c|c|c|c|c|}
\hline Age, (years) & $73 \pm 9$ & $73 \pm 12$ & 0.080 & 0.080 & $74 \pm 9$ & $75 \pm 11$ & 0.232 & 0.088 \\
\hline Male & $\begin{array}{l}300 \\
(47.5)\end{array}$ & $\begin{array}{l}547 \\
(49.3)\end{array}$ & 0.467 & 0.030 & $\begin{array}{l}185 \\
(49.6)\end{array}$ & $\begin{array}{l}190 \\
(50.9)\end{array}$ & 0.714 & 0.027 \\
\hline $\begin{array}{l}\text { Body mass index, } \\
\left(\mathrm{kg} / \mathrm{m}^{2}\right)\end{array}$ & $26 \pm 4$ & $24 \pm 4$ & $<0.001$ & $\mathrm{~N} / \mathrm{A}$ & $25 \pm 4$ & $25 \pm 4$ & 0.046 & N/A \\
\hline $\begin{array}{l}\text { Overweight } \\
\left(>30 \mathrm{~kg} / \mathrm{m}^{2}\right)\end{array}$ & $59(9.3)$ & $44(4.0)$ & $<0.001$ & 0.187 & $22(5.9)$ & $26(7.0)$ & 0.551 & 0.044 \\
\hline $\begin{array}{l}\text { Underweight } \\
\left(<20 \mathrm{~kg} / \mathrm{m}^{2}\right)\end{array}$ & $21(3.3)$ & $\begin{array}{l}116 \\
(10.5)\end{array}$ & $<0.001$ & 0.248 & $17(4.6)$ & $21(5.6)$ & 0.505 & 0.049 \\
\hline Hypertension & $\begin{array}{l}524 \\
(82.9)\end{array}$ & $\begin{array}{l}716 \\
(64.5)\end{array}$ & $<0.001$ & 0.433 & $\begin{array}{l}296 \\
(79.4)\end{array}$ & $\begin{array}{l}295 \\
(79.1)\end{array}$ & 0.928 & 0.007 \\
\hline Hyperlipidemia & $\begin{array}{l}319 \\
(50.5)\end{array}$ & $\begin{array}{l}293 \\
(26.4)\end{array}$ & $<0.001$ & 0.567 & $\begin{array}{l}160 \\
(42.9)\end{array}$ & $\begin{array}{l}163 \\
(43.7)\end{array}$ & 0.825 & 0.016 \\
\hline $\begin{array}{l}\text { Coronary artery } \\
\text { disease }\end{array}$ & $\begin{array}{l}187 \\
(29.6)\end{array}$ & $\begin{array}{l}162 \\
(14.6)\end{array}$ & $<0.001$ & 0.368 & $\begin{array}{l}79 \\
(21.2)\end{array}$ & $\begin{array}{l}74 \\
(19.8)\end{array}$ & 0.650 & 0.033 \\
\hline $\begin{array}{l}\text { Heart failure } \\
\text { history }\end{array}$ & $\begin{array}{l}130 \\
(20.6)\end{array}$ & $\begin{array}{l}183 \\
(16.5)\end{array}$ & 0.033 & 0.092 & $\begin{array}{l}63 \\
(16.9)\end{array}$ & $\begin{array}{l}63 \\
(16.9)\end{array}$ & 1.000 & $<0.001$ \\
\hline $\begin{array}{l}\text { Valvular heart } \\
\text { diseaset }\end{array}$ & $27(4.3)$ & $68(6.1)$ & 0.101 & 0.081 & $19(5.1)$ & $21(5.6)$ & 0.745 & 0.024 \\
\hline Atrial fibrillation & $\begin{array}{l}219 \\
(34.7)\end{array}$ & $\begin{array}{l}457 \\
(41.2)\end{array}$ & 0.007 & 0.188 & $\begin{array}{l}143 \\
(38.3)\end{array}$ & $\begin{array}{l}147 \\
(39.4)\end{array}$ & 0.764 & 0.022 \\
\hline $\begin{array}{l}\text { Cerebrovascular } \\
\text { accident }\end{array}$ & $\begin{array}{l}142 \\
(22.5)\end{array}$ & $\begin{array}{l}201 \\
(18.1)\end{array}$ & 0.028 & 0.077 & $\begin{array}{l}75 \\
(20.1)\end{array}$ & $\begin{array}{l}75 \\
(20.1)\end{array}$ & 1.000 & $<0.001$ \\
\hline $\begin{array}{l}\text { Chronic kidney } \\
\text { disease } \neq\end{array}$ & $\begin{array}{l}291 \\
(46.0)\end{array}$ & $\begin{array}{l}396 \\
(35.7)\end{array}$ & $<0.001$ & 0.210 & $\begin{array}{l}170 \\
(45.6)\end{array}$ & $\begin{array}{l}169 \\
(45.3)\end{array}$ & 0.941 & 0.005 \\
\hline $\begin{array}{l}\text { End-stage renal } \\
\text { disease§ }\end{array}$ & $\begin{array}{l}68 \\
(10.8)\end{array}$ & $46(4.1)$ & $<0.001$ & 0.254 & $20(5.4)$ & $20(5.4)$ & 1.000 & $<0.001$ \\
\hline $\begin{array}{l}\text { Chronic lung } \\
\text { disease }\end{array}$ & $27(4.3)$ & $54(4.9)$ & 0.572 & 0.073 & $14(3.8)$ & $16(4.3)$ & 0.709 & 0.027 \\
\hline $\begin{array}{l}\text { History of } \\
\text { cardiovascular } \\
\text { surgery }\end{array}$ & $31(4.9)$ & $55(5.0)$ & 0.963 & 0.014 & $17(4.6)$ & $16(4.3)$ & 0.859 & 0.013 \\
\hline History of cancer & 74 & 121 & 0.607 & 0.055 & 45 & 51 & 0.512 & 0.048 \\
\hline
\end{tabular}


(11.7) (10.9)

$(12.1)$

\section{Prescription for} drugs

\begin{tabular}{|c|c|c|c|c|c|c|c|c|}
\hline Beta-blocker & $\begin{array}{l}121 \\
(19.1)\end{array}$ & $\begin{array}{l}146 \\
(13.2)\end{array}$ & 0.001 & 0.177 & $\begin{array}{l}64 \\
(17.2)\end{array}$ & $\begin{array}{l}51 \\
(13.7)\end{array}$ & 0.187 & 0.097 \\
\hline ACEi/ARB & $\begin{array}{l}370 \\
(58.5)\end{array}$ & $\begin{array}{l}506 \\
(45.6)\end{array}$ & $<0.001$ & 0.297 & $\begin{array}{l}212 \\
(56.8)\end{array}$ & $\begin{array}{l}203 \\
(54.4)\end{array}$ & 0.507 & 0.049 \\
\hline Diuretic agents & $\begin{array}{l}212 \\
(33.5)\end{array}$ & $\begin{array}{l}257 \\
(23.2)\end{array}$ & $<0.001$ & 0.265 & $\begin{array}{l}113 \\
(30.3)\end{array}$ & $\begin{array}{l}114 \\
(30.6)\end{array}$ & 0.937 & 0.006 \\
\hline Statin & $\begin{array}{l}193 \\
(30.5)\end{array}$ & $\begin{array}{l}152 \\
(13.7)\end{array}$ & $<0.001$ & 0.439 & $\begin{array}{l}89 \\
(23.9)\end{array}$ & $\begin{array}{l}95 \\
(25.5)\end{array}$ & 0.610 & 0.037 \\
\hline
\end{tabular}

Diabetic therapy

\begin{tabular}{cll}
$\begin{array}{c}\text { Diet control } \\
\text { alone }\end{array}$ & 81 & 59 \\
$\begin{array}{c}\text { Oral antidiabetic } \\
\text { drugs }\end{array}$ & $472.8)$ & $(15.8)$ \\
\hline $\begin{array}{c}\text { Insulin-based } \\
\text { therapy }\end{array}$ & $79.7)$ & 282 \\
\hline
\end{tabular}

\section{Laboratory data}

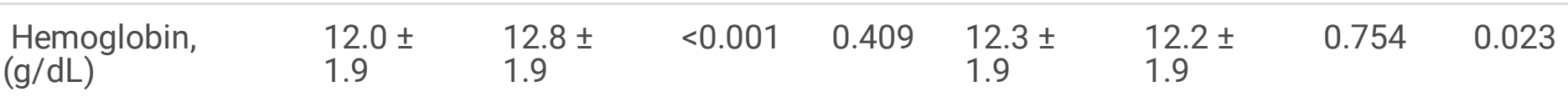

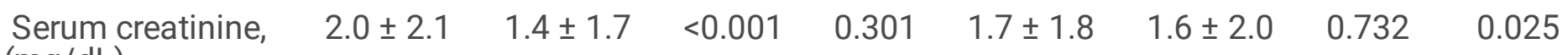
$(\mathrm{mg} / \mathrm{dL})$

eGFR,

$\left(\mathrm{mL} / \mathrm{min} / 1.73 \mathrm{~m}^{2}\right)$

HbA1c, (\%)

$\mathrm{LDL},(\mathrm{mg} / \mathrm{dL})$

$\mathrm{HDL},(\mathrm{mg} / \mathrm{dL})$

Triglyceride, $(\mathrm{mg} / \mathrm{dL})$

$\begin{array}{lllllllll}\begin{array}{l}\text { Albuminuria, } \\ (\mathrm{mg} / \mathrm{g})\end{array} & \begin{array}{l}141 \\ (22.3)\end{array} & 70(6.3) & <0.001 & \mathrm{~N} / \mathrm{A} & \begin{array}{l}89 \\ (23.9)\end{array} & 36(9.7) & <0.001 & \mathrm{~N} / \mathrm{A}\end{array}$

Microalbuminuria $\quad \stackrel{91}{(14.4)}$

$53(4.8) \quad<0.001 \quad \mathrm{~N} / \mathrm{A}$

Macroalbuminuria

\section{$54 \pm 30$}

$67 \pm 29$
N/A $\quad 58 \pm 28 \quad 61 \pm 29$

$0.171 \quad \mathrm{~N} / \mathrm{A}$

$\begin{array}{lllllll}7.1 \pm 1.3 & 5.7 \pm 0.4 & <0.001 & \mathrm{~N} / \mathrm{A} & 6.9 \pm 1.1 & 5.7 \pm 0.4 & <0.001\end{array} \mathrm{~N} / \mathrm{A}$

$90 \pm 34 \quad 101 \pm 34 \quad<0.001 \quad \mathrm{~N} / \mathrm{A}$

$89 \pm 33$

$101 \pm 39$

$0.001 \quad \mathrm{~N} / \mathrm{A}$

$47 \pm 13$

$53 \pm 16$

$<0.001 \quad \mathrm{~N} / \mathrm{A}$

$48 \pm 13$

$52 \pm 15$

0.005

N/A

$128 \pm 87$
141
$(22.3)$
91
$(14.4)$

$50(7.9)$

$17(1.5)$

$<0.001$

N/A

58

$25(6.7) \quad<0.001 \quad \mathrm{~N} / \mathrm{A}$

\section{Electrocardiographic and pacemaker data}

Patients with 
atrioventricular

block

Number of

pacemaker lead

Baseline QRS

duration (ms)

Pacing QRS

duration (ms)
(44.0)

(35.8)

(41.4)

(41.8)

$1.9+3.8$

$1.8 \pm 3.8 \quad 0.025$

0.107

$1.9 \pm 0.3$

$1.9 \pm 0.3$

0.661

0.034

$103 \pm 25 \quad 101 \pm 24 \quad 0.037$

0.127

$103 \pm 24$

$103 \pm 25$

0.928

0.007

$167 \pm 19 \quad 164 \pm 19 \quad 0.019$

0.154

$165 \pm 17$

$164 \pm 18$

0.180

0.098

\section{Pre-procedural} echocardiographic data

\begin{tabular}{lllllllll}
\hline LA size, $(\mathrm{mm})$ & $39 \pm 7$ & $38 \pm 8$ & 0.010 & N/A & $39 \pm 7$ & $39 \pm 8$ & 0.895 & N/A \\
\hline LVEDV, $(\mathrm{ml})$ & $114 \pm 35$ & $110 \pm 38$ & 0.049 & N/A & $114 \pm 33$ & $113 \pm 39$ & 0.676 & N/A \\
\hline LVESV, $(\mathrm{ml})$ & $39 \pm 23$ & $37 \pm 38$ & 0.065 & N/A & $38 \pm 21$ & $38 \pm 24$ & 0.898 & N/A \\
\hline LVEF, $(\%)$ & $67 \pm 12$ & $68 \pm 11$ & 0.042 & N/A & $68 \pm 11$ & $67 \pm 12$ & 0.876 & N/A
\end{tabular}

* Data are presented as mean \pm SD or number (\%) of patients.

† Defined as moderate to severe regurgitation or stenosis of aortic, mitral or tricuspid valves.

‡ Defined as eGFR lower than $60 \mathrm{~mL} / \mathrm{min} / 1.73 \mathrm{~m} 2$ without renal replacement therapy.

$\S$ Defined as the need for peritoneal dialysis, hemodialysis, or renal transplantation.

१ Defined as the history of asthma, or chronic obstructive pulmonary disease, or pulmonary fibrosis.

$\mathrm{ACEi} / \mathrm{ARB}=$ angiotensin converting enzyme inhibitors/angiotensin receptor blocker, eGFR = estimated glomerular filtration rate; $\mathrm{HbA1c}=$ hemoglobin $\mathrm{A} 1 \mathrm{c} ; \mathrm{HDL}=$ high-density lipoprotein; $\mathrm{LA}=$ left atrium; $\mathrm{LDL}$ = lowdensity lipoprotein; LVEDV = left ventricular end-diastolic volume; $L V E F=$ left ventricular ejection fraction; LVESV = left ventricular end-systolic volume; N/A = not applicable; SMD = standardized mean difference.

Table 2. Clinical outcomes of the patients with and without diabetes during a nearly 8-year follow-up period 


\begin{tabular}{|c|c|c|c|c|c|}
\hline \multicolumn{2}{|c|}{ Before matching } & \multicolumn{2}{|c|}{ After matching } & & \\
\hline $\begin{array}{l}\text { Diabetes } \\
(n=632)\end{array}$ & $\begin{array}{l}\text { Non- } \\
\text { Diabetes } \\
(n=1110)\end{array}$ & $\begin{array}{l}\mathrm{P} \\
\text { value }\end{array}$ & $\begin{array}{l}\text { Diabetes } \\
(n=373)\end{array}$ & $\begin{array}{l}\text { Non- } \\
\text { Diabetes } \\
(n=373)\end{array}$ & $\begin{array}{l}\mathrm{P} \\
\text { value }\end{array}$ \\
\hline
\end{tabular}

\section{Primary outcome}

\begin{tabular}{|c|c|c|c|c|c|c|}
\hline Cardiovascular events & $\begin{array}{l}125 \\
(19.8)\end{array}$ & $139(12.5)$ & $<0.001$ & $\begin{array}{l}70 \\
(18.8)\end{array}$ & $46(12.3)$ & 0.015 \\
\hline Heart failure hospitalization & $94(14.9)$ & $112(10.1)$ & 0.003 & $\begin{array}{l}57 \\
(15.3)\end{array}$ & $38(10.2)$ & 0.037 \\
\hline Acute myocardial infarction & $31(4.9)$ & $27(2.4)$ & 0.006 & $13(3.5)$ & $8(2.1)$ & 0.268 \\
\hline \multicolumn{7}{|l|}{ Secondary outcomes } \\
\hline $\begin{array}{l}\text { Pacing-induced } \\
\text { cardiomyopathy }\end{array}$ & $\begin{array}{l}105 \\
(16.6)\end{array}$ & $108(9.7)$ & $<0.001$ & $\begin{array}{l}64 \\
(17.2)\end{array}$ & $46(12.3)$ & 0.063 \\
\hline Cerebrovascular accident & $83(13.1)$ & $141(12.7)$ & 0.796 & $\begin{array}{l}56 \\
(15.0)\end{array}$ & $49(13.1)$ & 0.461 \\
\hline Cardiovascular mortality & $56(8.9)$ & $69(6.2)$ & 0.040 & $25(6.7)$ & $21(5.6)$ & 0.543 \\
\hline All-cause mortality & $\begin{array}{l}186 \\
(29.4)\end{array}$ & $238(21.4)$ & $<0.001$ & $\begin{array}{l}95 \\
(25.5)\end{array}$ & $77(20.6)$ & 0.118 \\
\hline
\end{tabular}

* Data are presented as number (\%) of patients.

Table 3. Univariate and multivariate analyses of predictors of cardiovascular events in the propensity scorematched patients 


\begin{tabular}{|c|c|c|c|c|}
\hline \multirow[t]{2}{*}{ Variable } & \multicolumn{2}{|l|}{ Univariate } & \multicolumn{2}{|l|}{ Multivariate } \\
\hline & $\mathrm{HR}(95 \% \mathrm{Cl})$ & $P$ value & $\mathrm{HR}(95 \% \mathrm{Cl})$ & $P$ value \\
\hline Age, (years) & $1.03(1.01-1.05)$ & 0.004 & $1.02(1.00-1.05)$ & 0.056 \\
\hline Female & $1.41(0.97-2.04)$ & 0.069 & $1.72(1.14-2.61)$ & 0.010 \\
\hline Body mass index, (kg/m2) & $0.98(0.93-1.03)$ & 0.393 & & \\
\hline Hypertension & $1.51(0.92-2.50)$ & 0.107 & & \\
\hline Diabetes & $1.65(1.14-2.39)$ & 0.008 & $1.54(1.04-2.29)$ & 0.031 \\
\hline Hyperlipidemia & $1.33(0.93-1.92)$ & 0.123 & & \\
\hline Coronary artery disease & $2.11(1.43-3.12)$ & $<0.001$ & $1.66(1.09-2.52)$ & 0.017 \\
\hline Heart failure history & $2.93(1.98-4.32)$ & $<0.001$ & $2.12(1.38-3.53)$ & 0.004 \\
\hline Atrial fibrillation & $1.69(1.18-2.44)$ & 0.005 & $1.17(0.78-1.75)$ & 0.445 \\
\hline Valvular heart disease & $1.92(1.00-3.67)$ & 0.050 & $0.65(0.29-1.42)$ & 0.275 \\
\hline History of cardiovascular surgery & $1.38(0.64-2.97)$ & 0.406 & & \\
\hline Cerebrovascular accident & $0.86(0.54-1.38)$ & 0.530 & & \\
\hline Chronic kidney disease & $2.69(1.83-3.97)$ & $<0.001$ & $2.01(1.32-3.07)$ & 0.001 \\
\hline Albuminuria & $2.45(1.62-3.70)$ & $<0.001$ & $1.56(1.00-2.43)$ & 0.049 \\
\hline Patients with atrioventricular block & $1.27(0.87-1.86)$ & 0.213 & & \\
\hline Pacing QRS duration (per 1 msec increment) & $1.01(1.00-1.02)$ & 0.007 & $1.01(1.00-1.02)$ & 0.083 \\
\hline Pre-procedural left atrium, (mm) & $1.02(1.00-1.04)$ & 0.035 & $1.01(0.98-1.03)$ & 0.629 \\
\hline Pre-procedural LVEDV, $\left(\mathrm{mm}^{2}\right)$ & $1.01(1.00-1.01)$ & 0.037 & $1.00(1.00-1.01)$ & 0.212 \\
\hline LVEF (\%) & $0.98(0.96-0.99)$ & 0.005 & $1.00(0.99-1.02)$ & 0.645 \\
\hline Prescription for beta-blocker & $1.33(0.83-2.13)$ & 0.243 & & \\
\hline Prescription for ACEi/ARB & $2.39(1.58-3.62)$ & $<0.001$ & $1.82(1.19-2.78)$ & 0.006 \\
\hline Prescription for diuretic agents & $2.07(1.43-2.98)$ & $<0.001$ & $1.24(0.82-1.87)$ & 0.308 \\
\hline Prescription for statin & $1.25(0.83-1.88)$ & 0.283 & & \\
\hline
\end{tabular}

*The definitions were the same as Table 1.

$\mathrm{ACEi} / \mathrm{ARB}=$ angiotensin converting enzyme inhibitors/angiotensin receptor blocker. $\mathrm{Cl}=$ confidence interval; HR: hazard ratio; LVEDV: left ventricular end-diastolic volume; LVEF: left ventricular ejection fraction. 


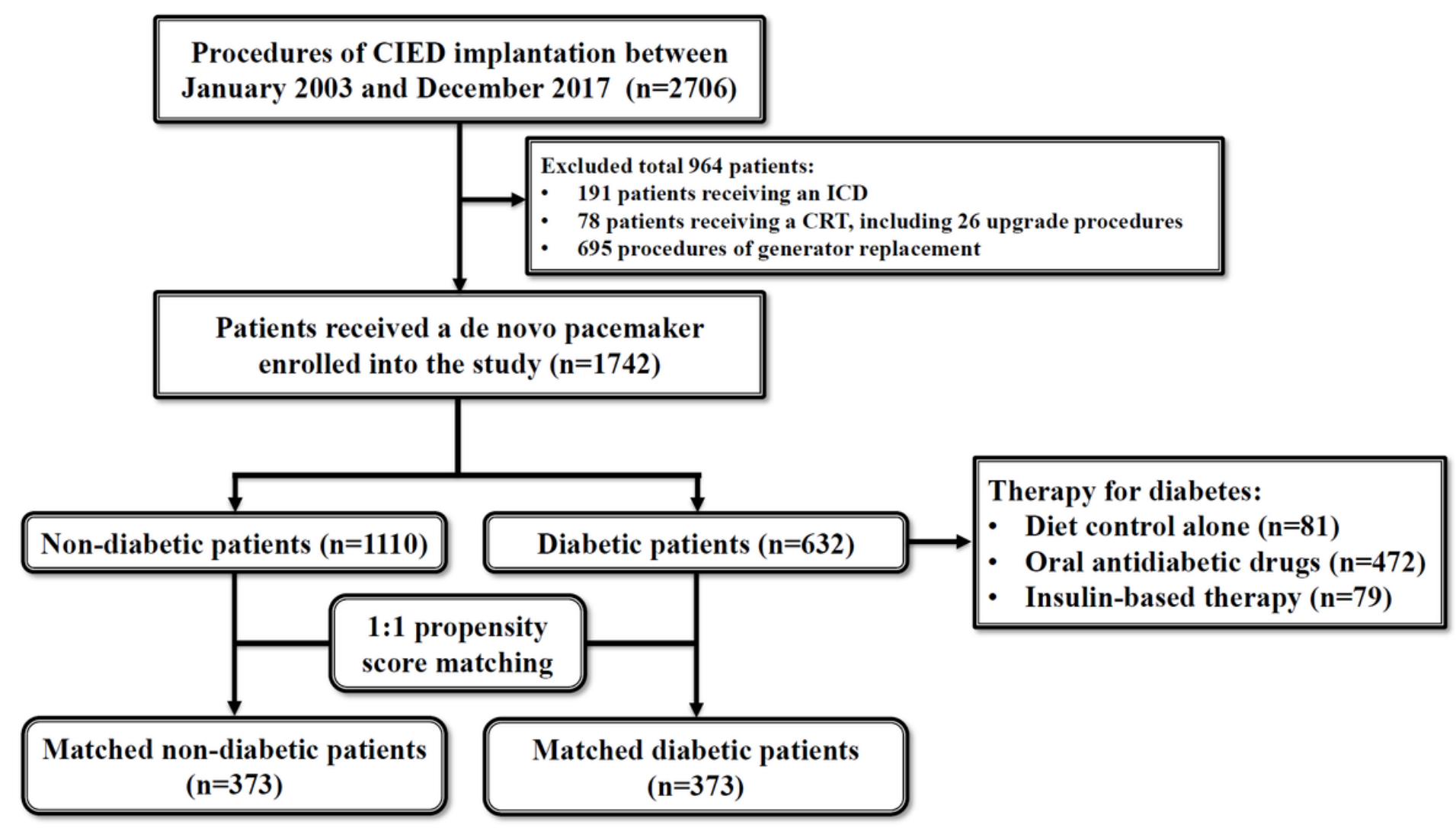

\section{Figure 1}

Flow chart of enrollment of patients receiving cardiac implantable electronic devices. CIED, cardiac implantable electronic devices; ICD, implantable cardioverter-defibrillator; CRT, cardiac resynchronization therapy 
(a) Cardiovascular events (before PSM)

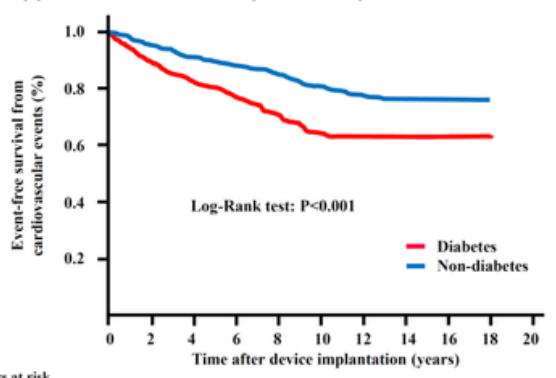

Numbers at risk Diabetes $\begin{array}{rrrrrrrrrr}632 & 436 & 289 & 160 & 90 & 47 & 23 & 14 & 5 & 0 \\ 1110 & 902 & 684 & 460 & 295 & 173 & 108 & 60 & 29 & 0\end{array}$

(d) Cardiovascular events (after PSM)

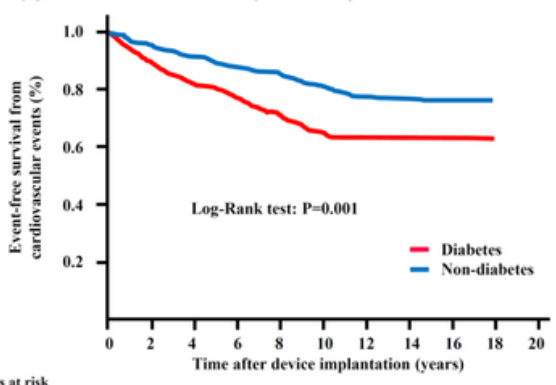

Numbers at risk Diabetes (b) Heart failure hospitalization (before PSM)

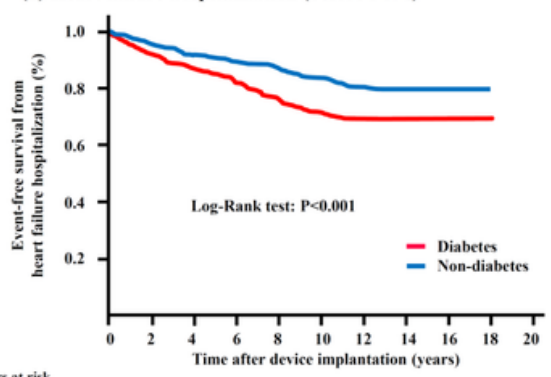

$\begin{array}{rrrrrrrrrr}632 & 443 & 293 & 163 & 92 & 51 & 26 & 16 & 5 & 0 \\ 1110 & 905 & 688 & 463 & 298 & 177 & 111 & 62 & 30 & 0\end{array}$

(e) Heart failure hospitalization (after PSM)

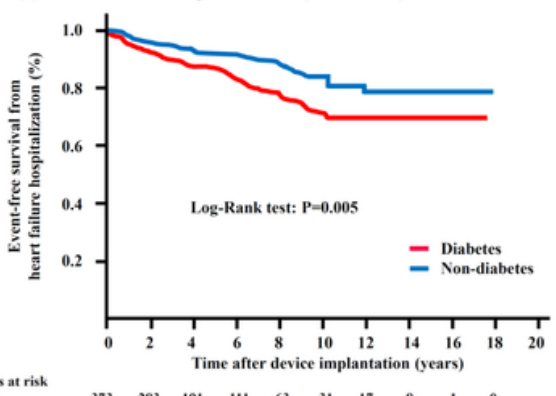

Numbers at risk
Diabetes

Diabetes
Non-diabetes (c) Acute myocardial infarction (before PSM)

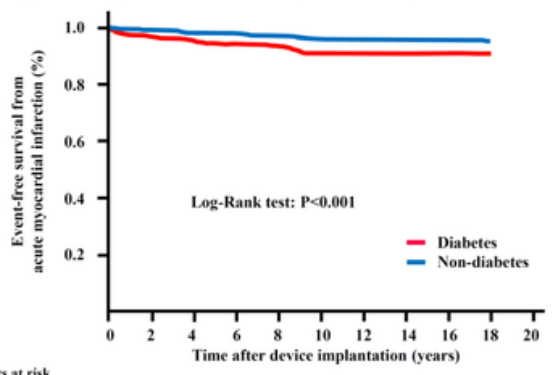

$\begin{array}{rrrrrrrrrr}632 & 462 & 314 & 179 & 103 & 54 & 28 & 17 & 6 & 0 \\ 1110 & 921 & 717 & 485 & 311 & 183 & 118 & 64 & 29 & 0\end{array}$

(f) Acute myocardial infarction (after PSM)

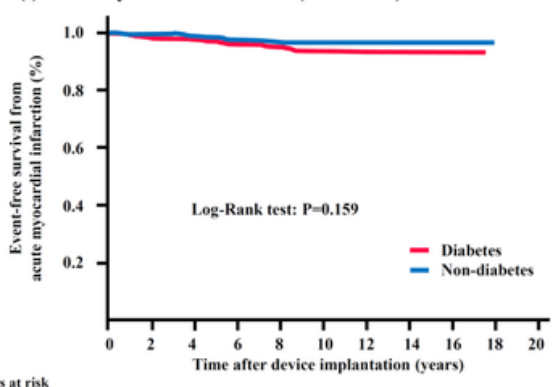

$\begin{array}{llllllllll}373 & 298 & 206 & 121 & 68 & 32 & 18 & 8 & 1 & 0 \\ 373 & 313 & 240 & 157 & 103 & 47 & 25 & 9 & 2 & 0\end{array}$

\section{Figure 2}

The Kaplan-Meier event-free survival curves of cardiovascular events (primary outcome) (Panel a, d), heart failure hospitalization (Panel b, e) and acute myocardial infarction (Panel $c, f$ ) between diabetic and nondiabetic groups before and after propensity score matching. PSM, propensity score matching

\section{Supplementary Files}

This is a list of supplementary files associated with this preprint. Click to download.

- SupplementaryTable1.docx 